\title{
Incidence, Population Density, and Spatial Heterogeneity of Plant-Parasitic Nematodes in Corn Fields in Ohio
}

\author{
Abasola C. M. Simon and Horacio D. Lopez-Nicora, Department of Plant Pathology, The Ohio State University, Columbus, OH 43210; \\ Laura E. Lindsey, Department of Horticulture and Crop Science, The Ohio State University, Columbus, OH 43210; Terry L. Niblack, De- \\ partment of Plant Pathology, The Ohio State University, Columbus, OH 43210; and Pierce A. Paul, ${ }^{\dagger}$ Department of Plant Pathology, The Ohio \\ State University, Ohio Agricultural Research and Development Center, Wooster, OH 44691
}

\begin{abstract}
Soil samples were collected from 425 corn fields in 28 Ohio counties between growth stages V3 and V6 during the 2013 and 2014 growing seasons. Ten morphological groups of plant-parasitic nematodes, namely spiral, lesion, lance, dagger, stunt, pin, ring, stubby-root, cyst, and "tylenchids" (several genera morphologically similar to members of the subfamily Tylenchinae [NCBI Taxonomy] including Cephelenchus, Filenchus, Malenchus, and Tylenchus) were identified. Eight species belonging to six of these groups were characterized. Spiral, tylenchids, lesion, pin, lance, stunt, and dagger nematodes were detected in 94, 96, 80, $57,48,48$, and $37 \%$ of the fields, respectively, whereas the stubby-root, cyst, and ring nematodes were present in fewer than $14 \%$ of the samples. Averaged across fields, the spiral, tylenchids, and pin nematodes had the

highest mean population densities. For all groups, incidence and population density varied among counties, and in some cases, among soil regions and cropping practices. Both population parameters were heterogeneous at multiple spatial scales, with the lowest heterogeneity among soil regions and the highest among fields within county and soil region. Estimated variances at the soil region level were not significantly different from zero for most of the nematodes evaluated. Stunt and lance were two of the most variable groups at all tested spatial scales. In general, the population densities were significantly more heterogeneous at the field level than at the county level. Findings from this study will be useful for developing sampling protocols and establishing on-farm trials to estimate losses and evaluate nematode management strategies.
\end{abstract}

Over the last few years, interest in plant-parasitic nematodes (PPN) associated with field corn, and consequently, the use of seed treated with nematode management products, have increased in the Midwestern United States. This is consistent with a recent increase in the overall use of other pesticides in agriculture, even in the absence of known disease or insect threats. Although PPNs are known to cause losses in field crops, including corn (Norton 1983), the threat posed by these pathogenic roundworms to corn production in Ohio is largely unknown. Recent research in Iowa showed that when baseline PPN populations were below established damage thresholds, nematode management products did not provide a yield benefit even if they were effective at reducing nematode population density (Batista da Silva 2013).

More than 60 different species of PPNs are known to feed on corn in North America (Norton 1983), of which the most common genera are the ectoparasitic Belonolaimus, Hemicycliophora, Helicotylenchus, Longidorus, Mesocriconema, Paratylenchus, Paratrichodorus, Xiphinema, and Tylenchorhynchus; the endoparasitic Meloidogyne and Pratylenchus; and the semiendoparasitic or endoparasitic Hoplolaimus (Norton 1984; Tylka et al. 2011a, 2011b; Yeates et al. 1993). Based on a survey conducted in Illinois, PPNs were found in each of the 550 fields sampled, at population densities ranging from 100 to $4,000+$ nematodes $/ 100 \mathrm{~cm}^{3}$ soil (T. L. Niblack and H. D. LopezNicora, personal communication). The spiral nematodes (Helicotylenchus spp.) were the most frequent, being found in $99 \%$ of the samples, in most cases at population densities exceeding 150 nematodes/ $100 \mathrm{~cm}^{3}$ soil. The lesion nematodes (Pratylenchus spp.) were the second most prevalent in the Illinois survey, being present in $84 \%$ of the fields. Members of this genus were found at population densities

${ }^{\dagger}$ Corresponding author: P. A. Paul; E-mail: paul.661@osu.edu

Funding: Salaries and research support for P. A. Paul, T. L. Niblack, A. C. M. Simon, and H. D. Lopez-Nicora were provided by state and federal funds to the Ohio Agricultural Research and Development Center.

Accepted for publication 24 June 2018.

(c) 2018 The American Phytopathological Society considered above moderate risk levels (26 nematodes $/ 100 \mathrm{~cm}^{3}$ soil) (Niblack 2009; Simon et al. 2018) in more than 50\% of the fields in which they were present. Similar findings were reported from Iowa, where PPNs were found in $92 \%$ of the 331 samples analyzed (Tylka et al. 2011a). Spiral and lesion nematodes were again the most frequently occurring groups, being present in 77 and $51 \%$ of the samples, respectively, at mean population densities of 87 and 21 nematodes $/ 100 \mathrm{~cm}^{3}$ soil, respectively (Tylka et al. 2011a).

The fact that nematodes were found at relatively high population densities in corn fields in Iowa and Illinois is not surprising. Current crop management practices such as conservation tillage and continuous corn may be contributing to the buildup of PPNs, because the frequency and distribution of these organisms may be influenced by soil type, edaphoclimatic conditions, cropping practices, and complex interactions among these factors. For example, Caveness (1974) found more Pratylenchus spp. in soil and corn root samples collected from conventionally tilled plots when compared with no-till plots, but Helicotylenchus and Meloidogyne were more abundant in notill plots than in conventionally tilled plots planted with corn in rotation with other crops. In contrast, Pratylenchus scribneri was more evenly distributed in no-till plots than in conventionally tilled plots in Indiana (Alby et al. 1983), and Thomas (1978) reported that higher population densities of Helicotylenchus spp., Pratylenchus spp., and Xiphinema spp. were found in no-till plots. Results from a study conducted by Parmelee and Alston (1986) in Georgia showed that the effects of tillage practices on nematode populations depended on when samples were collected. They found that tillage affected nematode population density, with monthly abundance being significantly greater in conventionally tilled plots than in no-till plots; however, during the summer, PPNs were more abundant in no-till than in conventionally tilled plots.

In spite of the similarities in crop production practices among Illinois, Iowa, and Ohio, data on nematode frequency and population density from the former two states cannot be extrapolated to the latter. This is because other factors such as soil $\mathrm{pH}$, organic matter, and texture, known to vary among the three states, may also affect nematode population structure (Florini et al. 1987; Norton and Hoffmann 1974; Wallace et al. 1993). Moreover, because the damage caused by any given species of nematode may vary with hybrid, crop management practices, weather conditions, and interactions among these 
factors (Norton 1983; Tylka et al. 2011a), no single population density will be adequate for estimating losses under all conditions (Tylka et al. 2011a). Therefore, one of the objectives of this study was to determine which genera and species of PPNs were most frequently found in corn fields in Ohio and at what population densities. Fifteen to 16 corn fields were sampled in 28 counties during the 2013 and 2014 growing seasons, and PPNs were identified and enumerated.

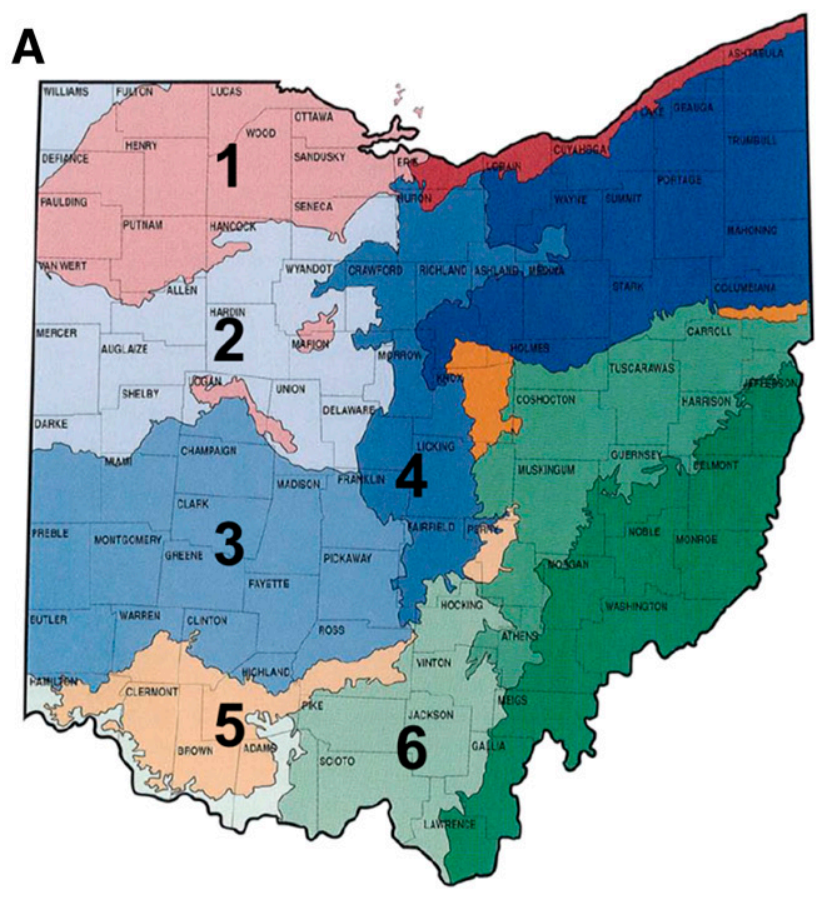

B

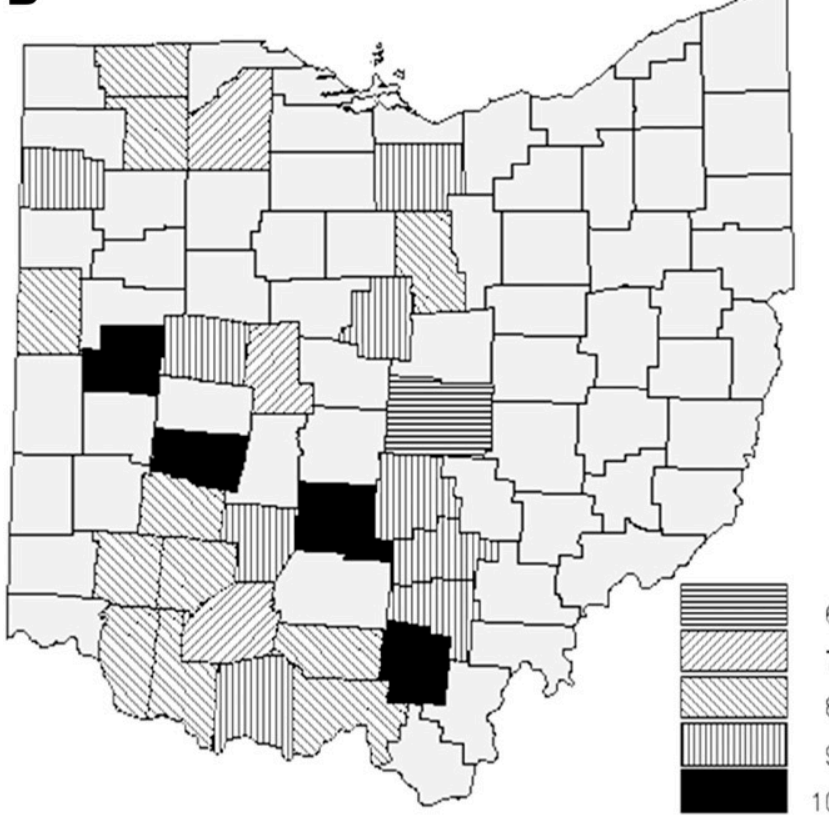

Fig. 1. Maps of the state of Ohio showing $A$, the six natural soil regions, and $B$, the 28 counties in which corn fields were sampled for plant-parasitic nematodes. In A, soil regions with 1 = Hoytville-Nappanee-Paulding-Toledo, 2 = Blount-Pewamo-Glynwood, $3=$ Miamian-Kokomo-Eldean, 4 = Bennington-Cardington-Centerburg, $5=$ ClermontRossmoyne-Avonburg-Cincinnati, and $6=$ Shelocta-Brownsville-LathamSteinsburg soil series as defined by the Ohio Department of Natural Resources. In $\mathbf{B}$, shaded regions are counties from which samples were collected, with the patterns representing the number of different morphological groups found in each of the counties sampled. Soil region map source: Ohio Department of Natural Resources.
Information pertaining to which genera and species are present, where, and at what population densities will be useful for establishing on-farm nematode trials to estimate losses and evaluate management programs.

A second objective of this study was to quantify heterogeneity in nematode presence and population density in corn fields in Ohio at multiple spatial scales. PPN populations are known to be highly variable within and among fields, but because a comprehensive nematode survey has never been conducted in corn fields in Ohio, there are no historical data from which the magnitude of such variability can be estimated. Generalized linear mixed models (Gbur et al. 2012; Stroup 2013) were fitted to the nematode incidence and population density data to estimate variability at the soil region, county within soil region, and field within county and soil region spatial levels. These estimates will be useful for establishing sampling protocols in future nematode surveys.

\section{Materials and Methods}

Soil sampling and nematode extraction. A total of 425 soil samples were collected during the 2013 and 2014 growing seasons between growth stages V3 and V6 (Abendroth et al. 2011) according to a stratified sampling plan. Specifically, 184 samples were collected from June 10 to July 2 in 2013, and 241 from June 10 to July 16 in 2014. The state was divided into strata based on six naturally occurring soil regions located in the western half of the state where the majority of the corn is cultivated (Fig. 1A; Table 1). A total of 28 counties (12 in 2013 and 16 in 2014) were sampled, and from each county, 15 or 16 fields were arbitrarily selected (Fig. 1B). Soil samples were taken from fields with different cropping histories, including fields with continuous corn (four or more years of corn-after-corn), corn-soybean rotation (the two crops rotated in the same field at least once in the last five years), and corn-soybean-wheat rotation (all three crops planted in the field at least once in the last 5 years). Crop husbandry and management of the selected fields were consistent with field corn production practices in the state (Barker et al. 2017). All fields were grown in monoculture and planted during the months of April and May. Land preparation across selected fields included conventional, vertical, minimum, or zero tillage.

Samples were collected in a zig-zag pattern across an 8-row section of each of the selected fields. A $2.54-\mathrm{cm}$-diameter soil probe was used to collect 18 to 20 soil cores to a depth of $30-50 \mathrm{~cm}$ from each sampled field and pooled into one composite sample. The volume of soil in each core ranged from 152 to $253 \mathrm{~cm}^{3}$, resulting in a composite sample of approximately 2,700 to $5,000 \mathrm{~cm}^{3}$. The soil probe was angled at approximately $45^{\circ}$ under the row of corn plants to collect samples within the rhizosphere. Undisturbed soil cores along with root fragments were placed into labeled plastic bags. Each sample was then placed into a cooler with cardboard and disposable ice packs, transported back to the laboratory, and stored at $4^{\circ} \mathrm{C}$ until processed.

From each individual composite soil sample collected per field, a single subsample of $100 \mathrm{~cm}^{3}$ was taken for nematode extraction by means of sieving, decanting, and centrifugal sucrose flotation technique (Jenkins 1964). A detailed description of the protocol can be found in Simon (2015). In brief, for each field (a composite sample) the soil cores were carefully broken, passed through a $1.27-\mathrm{cm}$ aperture sieve, and homogenized before a subsample was taken. Each subsample was added to a $1,000 \mathrm{ml}$ beaker containing $500 \mathrm{ml}$ tap water until the water level reached the $600 \mathrm{ml}$ mark, thus ensuring that approximately $100 \mathrm{~cm}^{3}$ soil was used. After careful mixing, the resulting soil-water suspension was poured and rinsed through stacked $850 \mu \mathrm{m}$ over $250 \mu \mathrm{m}$ aperture (20- over 60-mesh) sieves over a pail. Nematodes were then extracted from both the soil suspension in the pail and the materials captured in the sieves by means of the Baermann funnel technique (Jenkins 1964), identified, enumerated, and reported as a single total count for each morphological group per $100 \mathrm{~cm}^{3}$ soil.

Plant-parasitic nematode identification and enumeration. Morphological groups. PPNs were identified and grouped based on overall body shape and size, stylet shape and size, esophageal morphology, tail shape, metacorpus size, vulva position, stylet knob 
shape and size, shape when at rest, cephalic characteristics, and other features of gross body morphology (Mai and Mullin 1996). This was done with the aid of a stereoscope, a compound microscope (at $\times 40$ magnification), and a dichotomous key (Mai and Mullin 1996). Population levels, referred to here as abundance or population density (number of nematodes per $100 \mathrm{~cm}^{3}$ soil), were then determined by counting the number of nematodes of each group. Mean density was estimated as the sum of nematodes per $100 \mathrm{~cm}^{3}$ soil divided by the total number of samples in which the morphological group in question was detected. A similar approach was used to estimate mean abundance for different corn production practices and soil regions. The frequency or incidence (as a percentage) of each morphological group was also calculated by dividing the total number of samples in which that group was detected by the total number of samples collected and multiplying by 100 .

Species identification. Six of the most frequently occurring and abundant morphological groups were further identified to species based on morphological and molecular characteristics. Females and males (where applicable) were handpicked, fixed, mounted (Simon 2015), and then measured with the aid of a compound microscope and image-analysis software (Zeiss Axion A1 imager version 4.0, New York). Species were identified using diagnostic keys and original descriptions (Castillo and Vovlas 2007; Fortuner et al. 1984; Handoo 2000; Handoo and Golden 1989, 1992; Lamberti and Carone 1991; Raski 1975). For molecular characterization, DNA was extracted from 1 to 7 individuals (depending on nematode mass) of each of the species classified based on morphology. Nematodes were transferred individually to Eppendorf tubes containing $20 \mu \mathrm{l}$ of $0.25 \mathrm{M} \mathrm{NaOH}$, incubated overnight at room temperature, and thereafter heated to $99^{\circ} \mathrm{C}$ for $3 \mathrm{~min}$. Ten microliters of $0.25 \mathrm{M} \mathrm{HCl}$ and $5 \mu \mathrm{l}$ each of $0.5 \mathrm{M}$ Tris- $\mathrm{HCl}(\mathrm{pH} 8.0)$ and $2 \%$ Tritox X-100 were then added, and the mixture was incubated for another $3 \mathrm{~min}$ at $99^{\circ} \mathrm{C}$ (Hübschen et al. 2004). The DNA was then stored at $-80^{\circ} \mathrm{C}$ or used immediately for DNA amplification.

The resulting DNA was subjected to separate polymerase chain reaction (PCR) diagnostic assays for identification of each species. The D2-D3 expansion region of the 28S ribosomal RNA (rRNA) gene was amplified using forward primer ACAAGTACCGTGAGGG AAAGTTG and reverse primer TCGGAAGGAACCAGCTACTA (De Ley et al. 1999), or the 18S rRNA gene was amplified using forward primer CGCGAATRGCTCATTACAACAGC and reverse primer GGGCGGTATCTGATCGCC (Vrain et al. 1992). For each species, $10 \mu \mathrm{l}$ of DNA extract was added to the PCR mixture containing $10 \mu \mathrm{l}$ nuclease free water, $25 \mu \mathrm{l}$ DreamTaq PCR Master Mix (2X) (Thermo Fisher Scientific, Frederick, MD), and $2.5 \mu \mathrm{l}$ of each of the primers (forward and reverse). The thermal cycler program consisted of $3 \mathrm{~min}$ at $95^{\circ} \mathrm{C}$ (initial denaturation), 35 cycles of $30 \mathrm{~s}$ at $95^{\circ} \mathrm{C}$ (denaturation), 35 cycles of $30 \mathrm{~s}$ at $54^{\circ} \mathrm{C}$ (annealing), 35 cycles of $60 \mathrm{~s}$ at $72^{\circ} \mathrm{C}$ (extension), followed by a final extension step of 10 min at $72^{\circ} \mathrm{C}$. Ten microliters of PCR product was mixed with $2 \mu 1$ of $6 \times$ DNA loading dye, and $10 \mu l$ of the mixture was loaded on a $1.5 \%$ standard TAE buffered agarose gel stained with Invitrogen SYBR safe DNA gel stain (Thermo Fisher Scientific). After electrophoresis $(115 \mathrm{~V}, 2.0 \mathrm{~A}$ for $45 \mathrm{~min})$, the gel was visualized and photographed under UV light. The remaining PCR product was stored at $-20^{\circ} \mathrm{C}$ or used immediately for sequencing. An Applied Biosystems 3730 DNA Analyzer and BigDye cycle sequencing terminator chemistry was used for DNA sequencing (Plant-Microbe Genomics Facility, Ohio State University, Columbus, Ohio, USA). The sequences were deposited in GenBank and compared with previously deposited sequences by means of BLAST searches (Table 2).

Heterogeneity of plant-parasitic nematodes in corn fields in Ohio. For the six morphological groups characterized to species and the tylenchids, incidence (presence/absence) and abundance data were used to estimate variability in nematode presence and population density, respectively, at multiple spatial scales by fitting generalized linear mixed models (Gbur et al. 2012; Stroup 2013). Because nematodes were extracted from a single composite sample per field, each field was considered a sampling unit. The expected probability of a nematode of a certain morphological group being present in a given county was estimated as $p=Y / n$, where $Y$ is the number of fields testing positive for the nematode in question and $n$ is the total number of fields sampled per county (15 or 16). Since $p$ was assumed to have a conditional binomial distribution, PROC GLIMMIX of SAS (Littell et al. 2006) was used to fit generalized linear mixed

Table 2. Accession numbers A (GenBank deposit) and B (used for comparison), $\mathrm{E}$ value, and percent identity for plant-parasitic nematodes species identified from corn field in Ohio using molecular techniques ${ }^{\mathrm{a}}$

\begin{tabular}{|c|c|c|c|c|}
\hline Nematode species & Acc. No. A & Acc. No. B & $\begin{array}{c}\mathbf{E} \\
\text { value }\end{array}$ & Identi \\
\hline Xiphinema rivesi & KY849909 & JX912150.1 & $<0.001$ & 100 \\
\hline $\begin{array}{l}\text { Helicotylenchus } \\
\text { pseudorobustus }\end{array}$ & MG925220 & HM014264.1 & $<0.001$ & 99 \\
\hline Pratylenchus thornei & IG925219 & JX619 & $<0.001$ & 99 \\
\hline Pratylenchus scribneri ${ }^{\mathrm{b}}$ & MG925218 & KY424300.1 & $<0.001$ & 93 \\
\hline Pratylenchus crenatus ${ }^{\mathrm{b}}$ & MG925217 & EU669920.1 & $<0.001$ & 90 \\
\hline Hoplolaimus magnistylus & MF767410 & EU626788.1 & $<0.001$ & 98 \\
\hline Tylenchorhynchus claytoni & KY849908 & KJ934130.1 & $<0.001$ & 99 \\
\hline $\begin{array}{l}\text { Paratylenchus } \\
\text { neoamblycephalus }\end{array}$ & MG925221 & KY584086.1 & $<0.001$ & 99 \\
\hline
\end{tabular}

${ }^{a}$ Accession numbers $\mathrm{A}$ and $\mathrm{B}$ refer to the unique identifier assigned to the deposited or query sequence and the sequence used for comparison, respectively; E value is the expect value and identity refers to the percent similarity between the deposited and comparison sequences.

$\mathrm{b}$ Tentative classification because of relatively low sequence identity.

Table 1. Characteristics of the six soil regions in Ohio from which soil samples were collected during the 2013 and 2014 growing seasons for plant-parasitic nematode extraction, and number of counties sampled within each soil region and corn fields sampled within county and soil region

\begin{tabular}{|c|c|c|c|c|c|c|c|c|}
\hline \multirow[b]{2}{*}{ Region $^{\mathbf{a}}$} & \multirow[b]{2}{*}{ Soil series } & \multirow[b]{2}{*}{ County } & \multirow[b]{2}{*}{ Field } & \multicolumn{3}{|c|}{ Soil texture ${ }^{b}$} & \multirow[b]{2}{*}{ Rotation $^{\mathrm{c}}$} & \multirow[b]{2}{*}{ Tillage $^{d}$} \\
\hline & & & & Sand & Silt & $\overline{\text { Clay }}$ & & \\
\hline 1 & Hoytville-Nappanee-Paulding-Toledo & 4 & 61 & 43.82 & 31.92 & 24.26 & $19,29,13$ & $13,16,32$ \\
\hline 2 & Blount-Pewamo-Glynwood & 4 & 61 & 17.58 & 52.74 & 29.68 & $14,24,23$ & $14,08,39$ \\
\hline 3 & Miamian-Kokomo-Elden & 5 & 76 & 17.02 & 61.08 & 21.90 & $12,37,27$ & $26,24,26$ \\
\hline 4 & Bennington-Cardington-Centerburg & 5 & 76 & 23.65 & 54.32 & 22.03 & $15,37,24$ & $02,20,54$ \\
\hline 5 & Clermont-Rossmoyne-Avonburg-Cincinnati & 5 & 76 & 16.22 & 66.14 & 17.64 & $07,54,15$ & $35,16,25$ \\
\hline 6 & Shelocta-Brownsville-Latham-Steinsburg & 5 & 75 & 23.78 & 58.47 & 17.75 & $16,39,20$ & $21,15,39$ \\
\hline
\end{tabular}

a Region 1: approximately $60 \%$ of the soils in this region have more than $3 \%$ organic matter in the top $2.5 \mathrm{~cm}$, more than $27 \%$ clay in the topsoil, and the water table less than $0.30 \mathrm{~m}$ below the surface; Region 2: approximately $30 \%$ of the soils in this region have the characteristics described for Region 1; Region 3 : approximately $20 \%$ of the soils have the characteristics described for Region 1; Region 4: approximately $15 \%$ of the soils have the characteristics described for Region 1; Region 5: less than 3\% of the soils have more than 3\% organic matter and more than $27 \%$ clay in the topsoil, and $20 \%$ have the water table less than $0.30 \mathrm{~m}$ below the surface; Region 6: less than $2 \%$ of the soils in this region have the characteristics described for Region 1. Source: Ohio Department of Natural Resources.

${ }^{b}$ Mean percentage of sand, silt, and clay averaged across fields sampled in each soil region. Soil texture was determined as described in Simon et al. (2018).

${ }^{\mathrm{c}}$ Number of fields in each soil region under continuous corn, corn-soybean rotation, or corn-soybean-wheat rotation.

${ }^{\mathrm{d}}$ Number of fields in each soil region under no-till, conservation tillage (defined here as vertical or minimum tillage), or conventional tillage (includes all standard tillage operations). 
models to the data to estimate variances for the random effects of soil region $(R)$ and county within soil region $(C)$ on the expected value of $p$. Models were fitted to the logit link function of $p(\eta=\ln [p /(1-p)])$ as previously described (Gbur et al. 2012; Kriss et al. 2012; Stroup 2013). The models fitted to the data can be written as:

$$
\eta_{i j}=\beta+R_{i}+C(R)_{i j}
$$

where $\eta_{i j}$ is the logit link function, $\beta$ is the intercept or the overall mean on the link (logit) scale, $R_{i}$ is the random effect of the $i$ th soil region, and $C(R)_{i j}$ is the random effect of the $j$ th county within the $i$ th soil region.

The nematode abundance data (nematode count per $100 \mathrm{~cm}^{3}$ soil) was assumed to have a Poisson distribution with mean and variance equal to $\mu$; therefore, PROC GLIMMIX of SAS was again used to fit generalized linear mixed models to the data to estimate the random effects of soil region $(R)$, county within soil region $(C)$, and field within county within soil region $(F)$ on the expected population density of each morphological group. The model fitted to the log link function of the mean population density $(\eta=\log [\mu])$ can be written as:

$$
\eta_{i j k}=\beta+R_{i}+C(R)_{i j}+F(C R)_{i j k}
$$

where $\eta_{i j k}$ is the log link function (also known as the linear predictor), $\beta, R_{i}$, and $C(R)_{i j}$ are as defined above, and $F(C R)_{i j k}$ represents the random effect of the $k$ th field within the $j$ th county and $i$ th soil region. In both models, soil region and county, as well as field in model 2, were assumed to be independent and normally distributed, with mean 0 and constant variances of $\sigma_{R}^{2}, \sigma_{C}^{2}$, and $\sigma_{F}^{2}$, for soil region, county, and field, respectively.

Separate models were fitted for each morphological group, with maximum likelihood (by way of the method = laplace option in GLIMMIX) and pseudo-likelihood used as parameter estimation method for incidence and population density, respectively. Estimates of $\beta, \sigma_{R}^{2}, \sigma_{C}^{2}, \sigma_{F}^{2}$ and their standard errors were obtained. For incidence, likelihood ratio tests were used to determine the significance of the random effects and to test the null hypothesis of no difference in variance between soil region and county $\left(\sigma_{R}^{2}=\sigma_{C}^{2}\right)$. Profile confidence intervals around these statistics were calculated as explained in Kriss et al. (2012) by means of the covtest/cl(type=profile) statement in GLIMMIX. For population density, tests of statistical significance and estimates of confidence intervals were based on pseudolikelihood. After fitting the models, the inverse link function (Gbur et al. 2012; Stroup 2013) was used to obtain the estimated probability of a certain morphological group of nematodes being detected conditioned on the random effects.

Table 3. Morphometrics of females of the three species of Pratylenchus detected in corn fields sampled in Ohio between the V3 and V6 growth stages during the 2013 and 2014 growing seasons ${ }^{\mathrm{a}}$

\begin{tabular}{lccc}
\hline Characteristics & $\boldsymbol{P .}$ thornei & $\boldsymbol{P .}_{\text {scribneri }} \mathbf{b}$ & $\boldsymbol{P .}_{\text {crenatus }} \mathbf{b}$ \\
\hline $\mathrm{n}$ & 10 & 11 & 13 \\
$\mathrm{~L}$ & $460-580(510)$ & $450-600(530)$ & $420-620(510)$ \\
$\mathrm{a}$ & $23.7-29.5(27.0)$ & $21.2-29.1(24.6)$ & $20.2-31.8(26.7)$ \\
$\mathrm{b}$ & $3.5-5.1(4.2)$ & $4.5-6.4(5.4)$ & $4.1-5.4(4.7)$ \\
$\mathrm{c}$ & $16.4-19.0(17.8)$ & $16.4-22.0(19.4)$ & $17.0-23.2(19.3)$ \\
$\mathrm{V}$ & $75.4-78.4(76.6)$ & $77.7-83.0(81.7)$ & $77.3-86.9(79.7)$ \\
Stylet length & $17-18(17.0)$ & $16-18(17.0)$ & $16-19(17.0)$ \\
Dorsal gland orifice & $2.2-3.8(3.1)$ & $2.8-3.6(3.3)$ & $2.5-3.9(3.3)$ \\
Labial annules & 3 & 2 & 2 \\
Lateral incisures & 4 & 4 & 4 \\
Male & Very rare & Absent & Absent
\end{tabular}

${ }^{\mathrm{a}} \mathrm{n}=$ number of specimens on which measurements were made, $\mathrm{L}=$ body length, $\mathrm{a}=$ body length divided by the greatest body diameter, $\mathrm{b}=$ body length divided by the distance from the anterior end to the esophago-intestinal valve, $\mathrm{c}=$ body length divided by tail length, $\mathrm{V}=$ distance from the anterior end to the vulva divided by the body length multiplied by 100 . All measurements are in $\mu \mathrm{m}$.

b Tentative classification because of relatively low sequence identity (Table 2).

\section{Results}

Plant-parasitic nematodes in corn fields in Ohio. Morphological groups and species. PPNs accounted for over $50 \%$ of the total nematodes recovered in this survey. Microbivorous nematodes were found at varying levels, while fungivores, omnivores, and predators were detected in $3.8,3.3$, and $1.1 \%$ of the fields, respectively; the remaining $39.2 \%$ consisted of bacterial feeders. Ten morphological groups of PPNs were identified, namely spiral (primarily $\mathrm{Hel}$ icotylenchus), lesion (Pratylenchus), lance (Hoplolaimus), dagger (Xiphinema), stunt (primarily Tylenchorhynchus), pin (Paratylenchus), ring (Criconemella), stubby-root (Paratrichodorus), cyst (Heterodera), and "tylenchids" (several genera morphologically similar to members of the subfamily Tylenchinae (NCBI Taxonomy) including Cephelenchus, Filenchus, Malenchus, and Tylenchus).

Based on morphological and molecular characteristics, eight PPN species were characterized from six of the most frequently occurring morphological groups (Tables 2 and 3). The most commonly detected species were the spiral and lesion nematodes Helicotylenchus pseudorobustus and Pratylenchus thornei. Two other Pratylenchus species were tentatively classified as $P$. scribneri and $P$. crenatus based on molecular as well as morphological characteristics (Table 3 ). The species of stunt, lance, pin, and dagger nematodes characterized were Tylenchorhynchus claytoni (Fulton and Pickaway counties), Hoplolaimus magnistylus (Mercer County), Paratylenchus neoamblycephalus (Fulton and Union counties), and (Xiphinema rivesi (Fulton County), respectively.

Incidence and population density of PPN. All 10 morphological groups were detected in Clark, Jackson, Pickaway, and Shelby counties; 9 in Adams, Fairfield, Fayette, Hocking, Huron, Logan, Morrow, Paulding, and Vinton counties; 8 in Brown, Clermont, Clinton, Fulton, Greene, Henry, Mercer, Pike, Richland, Scioto, and Warren counties; 7 in Highland, Union, and Wood counties; and 6 in Licking county (Fig. 1B). Spiral, lesion, dagger, and pin nematodes were detected in all of the 28 counties sampled (Fig. 2A, B, D, and F); lance in all but Fulton and Henry counties (Fig. 2C); stunt in all but Licking, Morrow, and Vinton counties (Fig. 2E); stubby-root nematode was not detected in Highland, Licking, Mercer, Pike, Richland, Scioto, Union, and Wood counties; and cyst and ring nematodes were only detected in 14 and 11 of the 28 counties sampled, respectively.

Spiral nematodes and tylenchids had the highest incidence, being detected in 94 and $96 \%$ of the 425 fields sampled, respectively (Table 4). Lesion, pin, lance, stunt, and dagger were extracted from $80,57,48,48$, and $37 \%$ of the fields, respectively; whereas stubbyroot, cyst (based on juveniles only), and ring nematodes were detected in fewer than $14 \%$ of the samples. The spiral nematode was also the most abundant, with mean population density of 90 nematodes/ $100 \mathrm{~cm}^{3}$ soil, averaged across fields testing positive for this nematode (Table 4). The second most abundant group was the pin nematode, with a mean of 61 nematodes $/ 100 \mathrm{~cm}^{3}$ soil. Stunt, lance, and lesion were detected at mean population densities of 23,20 , and 16 nematodes/ $100 \mathrm{~cm}^{3}$ soil, respectively. Other morphological groups (ring, dagger, stubby-root, and cyst [based on juveniles only]) were detected at mean population densities below 11 nematodes $/ 100 \mathrm{~cm}^{3}$ soil (Table 4).

The mean abundance of spiral nematodes at the county level ranged from 16 to 208 nematodes $/ 100 \mathrm{~cm}^{3}$ soil, with Union County having the highest and Pike the lowest mean population densities (Fig. 2A). For the lesion and lance nematodes, Fulton and Scioto (37 nematodes $/ 100 \mathrm{~cm}^{3}$ soil) and Clermont (48 nematodes $/ 100 \mathrm{~cm}^{3}$ soil) and Brown ( 40 nematodes $/ 100 \mathrm{~cm}^{3}$ soil) counties had the highest mean densities, respectively (Fig. 2B and C). On the other hand, the lance nematode was not detected in either Henry or Fulton counties, and lesion nematode was recorded at the lowest population level in Clinton County (a mean of 4 nematodes $/ 100 \mathrm{~cm}^{3}$ soil). Among fields testing positive for the pin nematode, Union and Paulding counties had the highest (245 and 201 nematodes $/ 100 \mathrm{~cm}^{3}$ soil, respectively) and Wood the lowest (6 nematodes $/ 100 \mathrm{~cm}^{3}$ soil) mean population density (Fig. 2F), whereas Fulton had the highest mean abundance of the stunt and dagger nematodes (Fig. 2D and E). 
Tylenchids, ring, cyst, and stubby-root nematodes were most abundant in Clark, Adams, Jackson, and Fulton counties (not shown in Figure 2).

Plant-parasitic nematode population density by cropping practice and soil region. Spiral was clearly the most abundant of the 10 morphological groups in all three cropping systems, with a
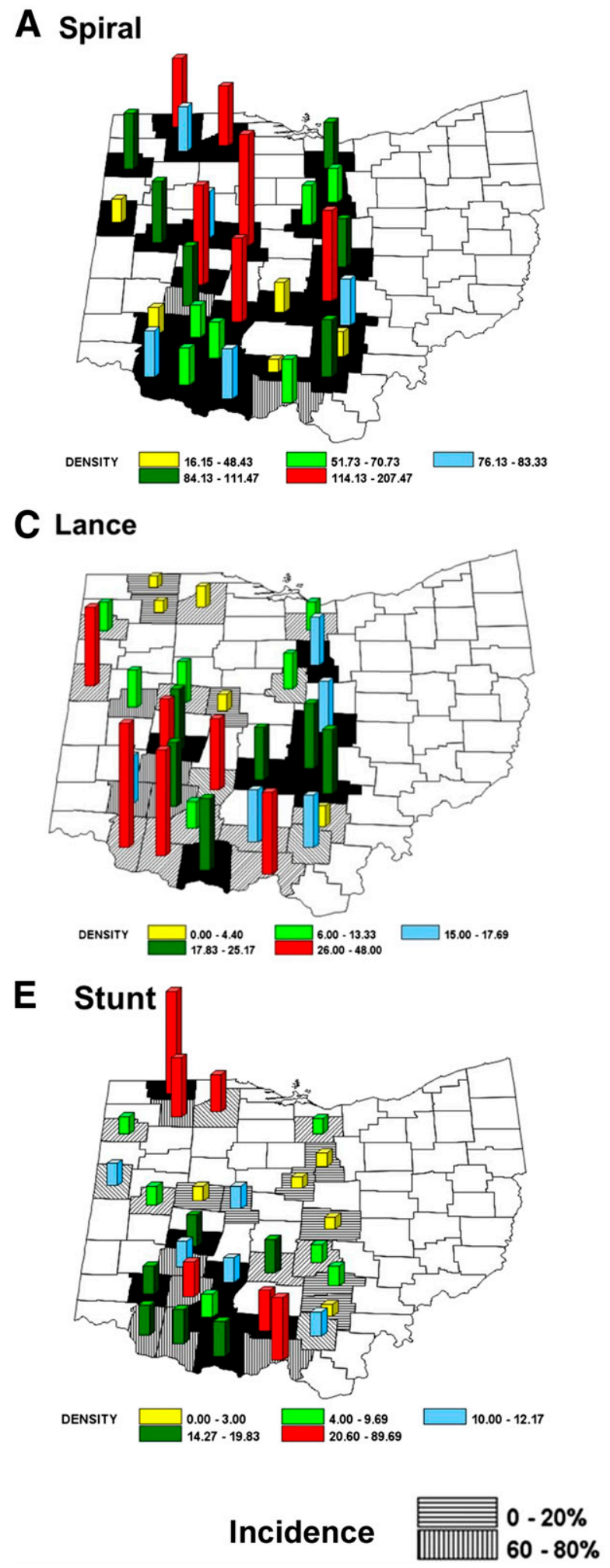

higher mean population density in fields under continuous corn (CC) than under corn-soybean (CS) or corn-soybean-wheat (CSW) rotation (Fig. 3A, C, and E). Similar trends were observed for the stunt and lance nematodes, for which mean population densities were higher in the CC than in the CS or CSW cropping sequences. Conversely, the pin nematode was more abundant in fields under rotation
B Lesion

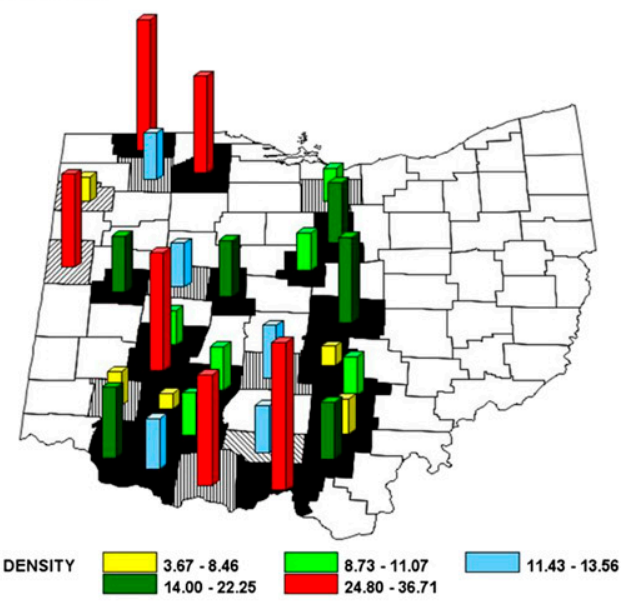

D Dagger

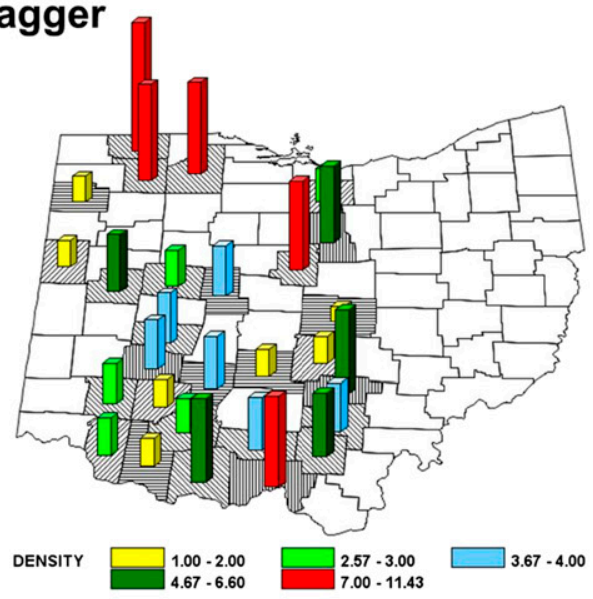

F Pin

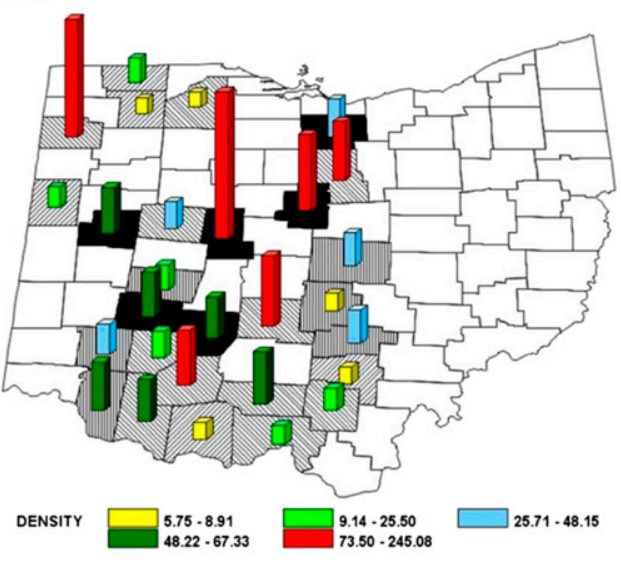

$20-40 \%$
$80-100 \%$

Fig. 2. Maps of Ohio showing county-level incidence (patterns) and mean population density (bars) of A, spiral, B, lesion, C, lance, D, dagger, E, stunt, and F, pin nematodes in soil samples collected from corn fields between growth stages V3 and V6 in 2013 and 2014. Three species of lesion (Pratylenchus thornei, $P$. scribneri, and $P$. crenatus) and one each of spiral (Helicotylenchus pseudorobustus), lance (Hoplolaimus magnistylus), dagger (Xiphinema rivesi), stunt (Tylenchorhynchus claytoni), and pin (Paratylenchus neoamblycephalus) nematodes were identified. Counties in white were not sampled. Incidence was estimated as the percentage of positive fields out of 15 to 16 fields sampled per county, whereas mean population density was estimated as the mean number of nematodes per $100 \mathrm{~cm}^{3}$ soil averaged across positive samples. 
than under continuous corn. For the other morphological groups, the mean population densities were fairly consistent across the three cropping sequences (Fig. 3A, C, and E).

Mean population densities in tilled fields were higher for the spiral nematode than for the other morphological groups (Fig. 3B and D). However, in the no-till system, the pin nematode was the most abundant, and the second most abundant for the other two tillage systems. Among fields testing positive for the lesion and stunt nematodes, the mean population densities were higher in fields under conventional tillage than under conservation tillage or no-till systems (Fig. 3B, $\mathrm{D}$, and F). Abundance was highest for the lance nematode in the conservation tillage system, whereas the tylenchids, dagger, stubby-root, and cyst (based on juveniles only) nematodes showed consistent mean population densities across the three tillage systems. Fields under no-till had the highest abundance of the ring nematode when compared with tilled fields (Fig. 3F).

With the exception of the ring and cyst nematodes, which were not detected in soil regions 1 and 5, respectively, all morphological groups were detected in the six soil regions sampled (Fig. 4). Relative to the other regions, region 6 had the lowest overall mean nematode population density. In any given soil region, the spiral nematode was generally predominant, with the highest mean densities in regions 1,2 , and 3 , and the lowest in regions 5 and 6 . The pin nematodes were most abundant in soil region 2 and least abundant in region 6 . Region 1 had the highest densities of stunt and lesion nematodes, whereas soil region 5 had the highest densities of ring and lance nematodes compared with the other regions (Fig. 4). Population densities of the stubby-root nematodes and "tylenchids" were similar across soil regions.

Heterogeneity of plant-parasitic nematodes in corn fields in Ohio. Incidence. The estimated mean proportion (incidence on the logit $[\hat{\beta}]$ and original $[\hat{p}]$ scales) of samples testing positive for the seven morphological groups of PPNs most frequently encountered in this study are presented in Table 5, along with soil regionand county-within-soil region-level variance estimates $\left(\hat{\sigma}_{R}^{2}\right.$ and $\hat{\sigma}_{C}^{2}$, respectively). Based on these statistics, incidence varied among morphological groups at both spatial scales (Fig. 5). There was a wider range of incidence heterogeneity at the county level than at the soil

Table 4. Incidence and population density of 10 morphological groups of plant-parasitic nematodes detected in corn fields sampled in Ohio between the V 3 and V6 growth stages during the 2013 and 2014 growing seasons

\begin{tabular}{lccrr}
\hline Nematode $^{\mathbf{a}}$ & Incidence $^{\mathbf{b}}$ & Density $^{\mathbf{c}}$ & SD $^{\mathbf{d}}$ & Maximum $^{\mathbf{e}}$ \\
\hline Cyst (Heterodera) & 11 & $7(1)$ & 12 & 58 \\
Dagger (Xiphinema) & 37 & $5(2)$ & 5 & 26 \\
Lance (Hoplolaimus) & 48 & $20(7)$ & 21 & 106 \\
Lesion (Pratylenchus) & 80 & $16(13)$ & 24 & 300 \\
Pin (Paratylenchus) & 57 & $61(34)$ & 137 & 1,164 \\
Ring (Criconemella) & 5 & $10(<1)$ & 18 & 82 \\
Spiral (Helicotylenchus) & 94 & $90(84)$ & 109 & 990 \\
Stubby-root (Paratrichodorus) & 13 & $4(1)$ & 8 & 56 \\
Stunt (Tylenchorhynchus) & 48 & $23(11)$ & 37 & 240 \\
Tylenchids & 96 & $25(23)$ & 26 & 218 \\
\hline
\end{tabular}

${ }^{\text {a }}$ Three species of lesion (Pratylenchus thornei, P. scribneri, and P. crenatus) and one each of spiral (Helicotylenchus pseudorobustus), lance (Hoplolaimus magnistylus), dagger (Xiphinema rivesi), stunt (Tylenchorhynchus claytoni), and pin (Paratylenchus neoamblycephalus) nematodes were identified. The group tylenchids represents several genera of plant parasites and other trophic groups that are morphologically similar to members of the subfamily Tylenchinae (NCBI Taxonomy) including Cephelenchus, Filenchus, Malenchus, and Tylenchus.

${ }^{b}$ Percentage of 425 samples that were positive for nematodes of a certain morphological group (total number of samples in which the morphological group was detected divided by 425 , multiplied by 100).

${ }^{c}$ Mean population density (nematodes per $100 \mathrm{~cm}^{3}$ soil) averaged across positive (nonzero) samples and across all samples, including those with zero (in parentheses).

${ }^{\mathrm{d}} \mathrm{SD}=$ standard deviation of mean population density averaged across positive samples.

e Maximum single-field (composite sample) population density (nematodes per $100 \mathrm{~cm}^{3}$ soil). region level, with $\hat{\sigma}_{C}^{2}$ values between 0.16 and 2.28 compared with $\hat{\sigma}_{R}^{2}$ values between 0 and 1.7. For three of the seven nematode groups (tylenchids, lesion, and dagger), $\hat{\sigma}_{R}^{2}$ was estimated to be zero, whereas for the two most heterogeneous groups (lance and stunt in Figure 5A and Table 5), the estimates were significantly different from zero $(P<0.05)$. Estimated variances for the incidence of spiral and pin nematodes at the soil region level were marginally significant $(P<0.10)$.

Somewhat different trends were observed in terms of nematode incidence heterogeneity at the county level (Fig. 5B). For all but one morphological group (the spiral nematodes), $\hat{\sigma}_{C}^{2}$ was significantly different from zero $(P<0.001)$. Tylenchids was the most variable group across counties, followed by lance, stunt, lesion, and pin, in that order (Fig. 5B). Although the overall incidence of PPNs was more variable at the county level than at the soil region level (based on the fact that $\hat{\sigma}_{C}^{2}$ was statistically significant for more groups than $\hat{\sigma}_{R}^{2}$ ), results from the likelihood ratio test showed that differences in estimated variances between the two spatial scales were not statistically significant for any of the nematodes $(P>0.40$; Table 5$)$.

Population density. The heterogeneity of PPN population densities was quantified at multiple spatial scales: soil region, county within soil region, and field within county and soil region. As was the case with nematode incidence, the lowest level of heterogeneity for all morphological groups evaluated was among soil region, with the estimated variances $\left(\hat{\sigma}_{R}^{2}\right)$ of either 0 or not significantly different from zero for five of the seven groups (Table 6). The population densities (also referred to here as abundance) of the stunt and lance nematodes were the most variable among soil regions, with the estimated variance parameter significantly greater than zero $(P<0.05)$ for both groups (Fig. 6A).

For all morphological groups evaluated in this study, estimated variances at the county within soil region and field within county within soil region levels were significantly greater than zero $(P<$ 0.001 , Table 6). At both spatial scales, populations of the lance, stunt, and pin nematodes were the most variable. The county-level population variance estimate was highest for the stunt nematode, followed by the pin, lance, dagger, lesion, tylenchids, and spiral nematodes (Fig. 6B), whereas the field-level estimate was highest for the pin nematode, followed by the lance, stunt, spiral, dagger, lesion nematodes, and tylenchids, in that order (Fig. 6C).

\section{Discussion}

Ten morphological groups of PPNs were identified in this study, including spiral, lesion, lance, stunt, dagger, pin, stubby-root, ring, cyst, and tylenchids (several members of the subfamily Tylenchinae counted together as a single group), with at least one group detected in each of the 425 fields sampled. Eight species were characterized, including three important Pratylenchus spp., P. scribneri, P. thornei, and $P$. crenatus. These are economically important and can cause serious damage to agronomic crops including corn, wheat, and soybean (Lawn and Noel 1986; Norton 1983; Smiley et al. 2005), the most widely grown field crops in Ohio. To our knowledge, Hoplolaimus magnistylus (accession number MF767410), Tylenchorhynchus claytoni (accession number KY849908), and Xiphinema rivesi (accession number KY849909), three of the species characterized in this study, have not been previously reported in corn fields in Ohio. These as well as the other two identified species, Helicotylenchus pseudorobustus and Paratylenchus neoamblycephalus, have been previously reported as pathogens of corn (Nelson 1955; Norton et al. 1978). In fact, the high population density of the latter species in fields under corn-soybean rotation suggests that it may also be a pathogen of soybean. Through generalized linear mixed model analyses of the incidence and population density data, we quantified the heterogeneity of the most frequently detected groups at multiple spatial scales and found the greatest variability in population density at the lowest level (fields within county and soil region) in the spatial hierarchy. Populations of lance, dagger, stunt, and pin nematodes were much more variable among fields than populations of spiral, tylenchids, and lesion nematodes. 
Results from similar studies conducted in Illinois and Iowa were comparable to those reported here in terms of the morphological groups detected and their frequency (incidence) across the state (Tylka et al. 2011a; T. L. Niblack and H. D. Lopez-Nicora, personal communication). All of the groups detected in Illinois were found in Ohio, with the exception of Longidorus (needle) and Meloidogyne (root-knot), and a similar set was detected in Iowa, except for Longidorus, which was found in Iowa but not in Ohio. The spiral and

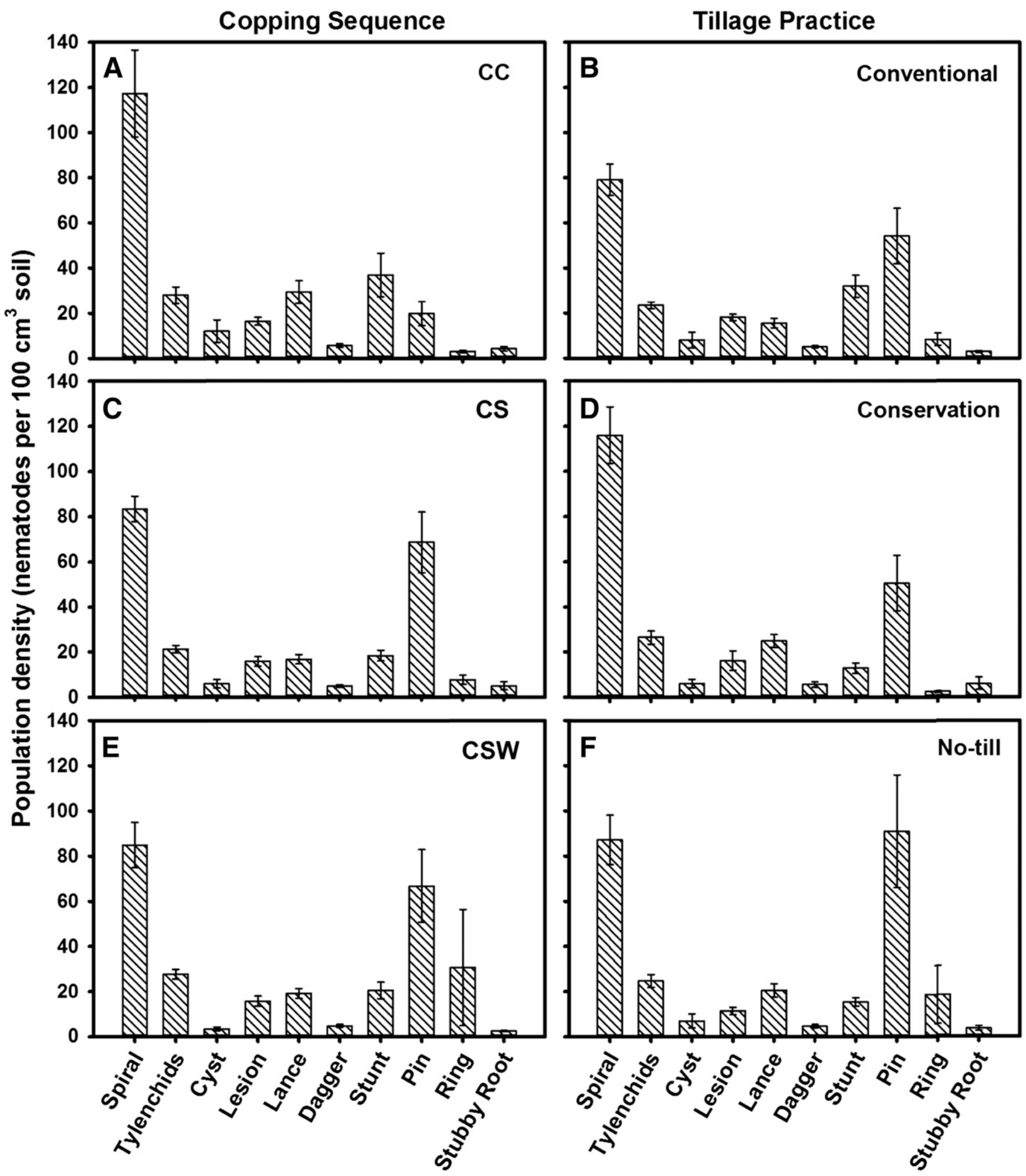

Fig. 3. Mean population density (nematodes per $100 \mathrm{~cm}^{3}$ soil) of 10 morphological groups of plant-parasitic nematodes (spiral, tylenchids, cyst, lesion, lance, dagger, stunt, pin, ring, and stubby-root) in Ohio corn fields sampled between the V3 and V6 growth stages during the 2013 and 2014 growing seasons. Three species of lesion (Pratylenchus thornei, $P$. scribneri, and P. crenatus) and one each of spiral (Helicotylenchus pseudorobustus), lance (Hoplolaimus magnistylus), dagger (Xiphinema rivesi), stunt (Tylenchorhynchus claytoni), and pin (Paratylenchus neoamblycephalus) nematodes were identified. The group tylenchids represents several genera morphologically similar to members of the subfamily Tylenchinae (NCBI Taxonomy) including Cephelenchus, Filenchus, Malenchus, and Tylenchus. Samples were collected from fields under different cropping sequences, $\mathbf{A}(C C=$ continuous corn, $n=83), \mathbf{C}$ (CS = corn-soybean rotation, $n=220)$, and $\mathbf{E}(C S W=$ corn-soybean-wheat rotation, $n=122)$; and tillage practices, $\mathbf{B}$ (conventional $=$ includes all standard tillage operations, $n=215$ ), $\mathbf{D}$ (conservation $=$ vertical or minimum tillage, $n=99$ ), and $\mathbf{F}$ (no-till, $n=111$ ). Bars represent means across positive samples and the error bars represent standard errors of the means. 
lesion nematodes were also among the most frequently encountered in both Illinois and Iowa, but despite its high incidence, population densities of spiral nematodes were generally low in all three states. This suggests that it is probably not a threat to corn production in Ohio.
However, further research will be needed to determine how damaging spiral nematodes are under conditions in Ohio, and at what population levels. In the absence of Ohio-specific data, the damage threshold of $500-1,000$ nematodes $/ 100 \mathrm{~cm}^{3}$ soil proposed by Tylka et al. (2011a) can be used as a guide to understand what the numbers

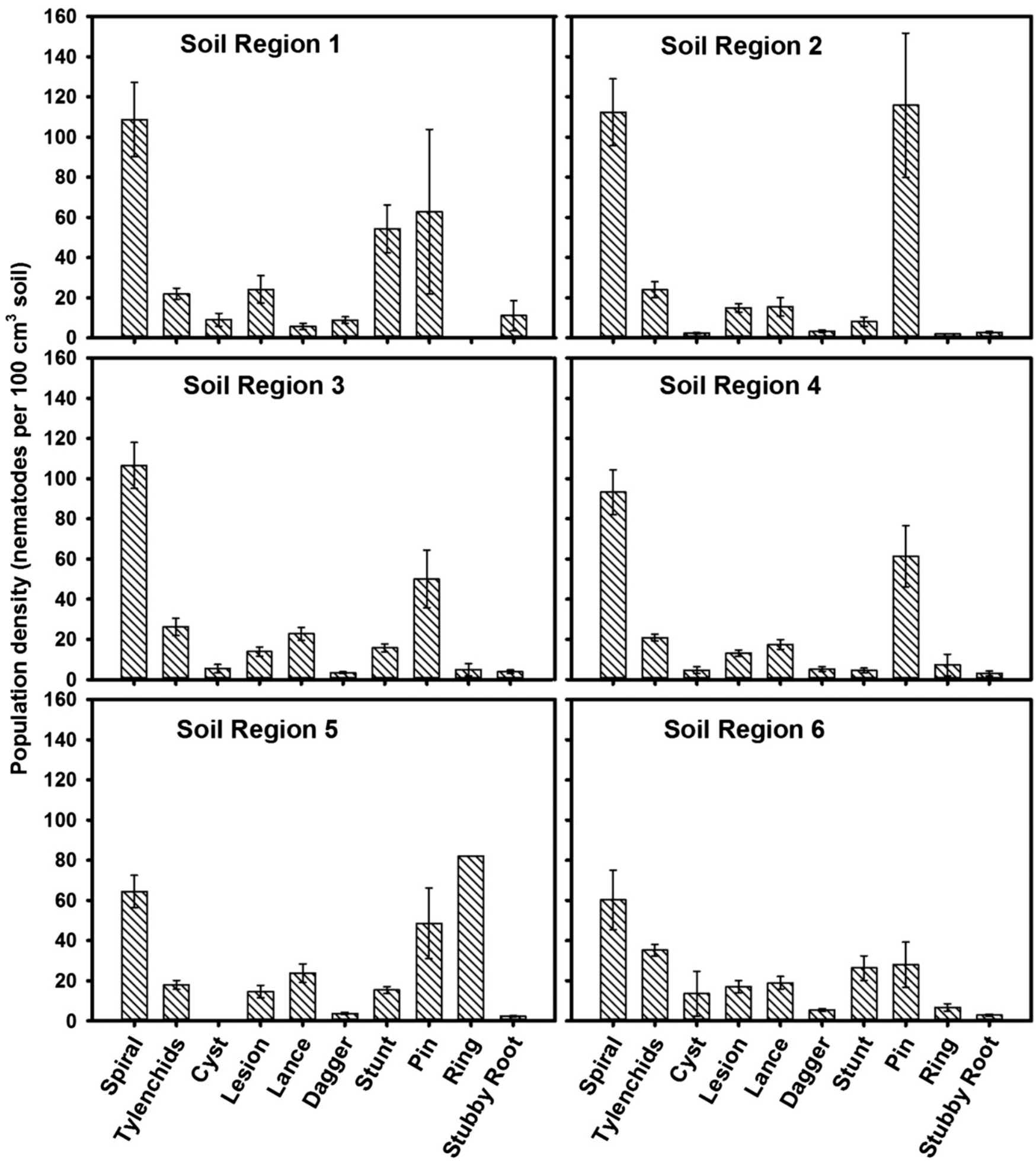

Fig. 4. Mean population density (nematodes per $100 \mathrm{~cm}^{3}$ soil) of 10 morphological groups of plant-parasitic nematodes (spiral, tylenchids, cyst, lesion, lance, dagger, stunt, pin, ring, and stubby-root) in Ohio corn fields sampled between the V3 and V6 growth stages during the 2013 and 2014 growing seasons. Three species of lesion (Pratylenchus thornei, $P$. scribneri, and P. crenatus) and one each of spiral (Helicotylenchus pseudorobustus), lance (Hoplolaimus magnistylus), dagger (Xiphinema rivesi), stunt (Tylenchorhynchus claytoni), and pin (Paratylenchus neoamblycephalus) nematodes were identified. The group tylenchids represents several genera morphologically similar to members of the subfamily Tylenchinae (NCBI Taxonomy) including Cephelenchus, Filenchus, Malenchus, and Tylenchus. Samples were collected from fields in six naturally occurring soil regions consisting of different soil series as defined by the Ohio Department of Natural Resources ( $1=$ Hoytville-Nappanee-Paulding-Toledo [ $n=61$ ], $2=$ Blount-PewamoGlynwood [ $n=61$ ], $3=$ Miamian-Kokomo-Eldean [ $n=76$ ], $4=$ Bennington-Cardington-Centerburg $[n=76], 5=$ Clermont-Rossmoyne-Avonburg-Cincinnati $[n=76]$, and $6=$ Shelocta-Brownsville-Latham-Steinsburg $[n=75]$ ). Bars represent means across positive samples, and the error bars represent standard errors of the means. 
from our study mean in terms of potential threat to corn production. Six of the 28 Ohio counties sampled had at least one field with spiral nematode populations at or close to the damage threshold. Since the species of spiral nematode identified in this study, Helicotylenchus pseudorobustus, is known to negatively affect corn yield (Norton et al. 1978), these counties could potentially have problems with this nematode, and as such should be immediate targets for more detailed investigations.

The lesion nematode, one of the most economically damaging group of PPNs, was the second most frequently occurring (not including the tylenchids), being present in $80 \%$ of fields sampled. High incidence of the lesion nematode was also reported in corn fields in Illinois and Iowa (Tylka et al. 2011a; T. L. Niblack and H. D. LopezNicora, personal communication), wheat fields in Colorado (Todd et al. 2014), and soybean fields in Missouri (Niblack 1992). This suggests that corn, wheat, and soybean are suitable hosts for species of this group, and provides some explanation for its high frequency in Ohio where all three crops are widely cultivated in rotation. Mean population densities in the three cropping sequences evaluated in this study were very similar, approximately 16 nematodes $/ 100 \mathrm{~cm}^{3}$ soil. This was slightly lower than the densities of 26 and 21 nematodes/ $100 \mathrm{~cm}^{3}$ soil, respectively, reported in Illinois and Iowa (Tylka et al. 2011a; T. L. Niblack and H. D. Lopez-Nicora, personal communication).

The suggested severe and moderate risk thresholds for this nematode in Illinois were 51-100 and 26-50 nematodes $/ 100 \mathrm{~cm}^{3}$ of soil, respectively (Niblack 2009). In Ohio, 24 of the 28 counties sampled had at least one field with population density at the moderate- or severe-risk threshold levels, suggesting that fields in these counties may be at risk for damage by lesion nematodes. The three species identified in this study, P. scribneri, P. crenatus, and P. thornei, are known to negatively impact yield in corn and other field crops. $P$. scribneri, common in irrigated corn fields in sandy soils (Todd 1991), and $P$. hexincisus, perhaps the most important species of lesion nematode in the Midwest (Zirakparvar 1980), are two species capable of causing losses in corn. P. brachyurus was responsible for over 25\% yield reduction in corn in Nigeria (Egunjobi 1974), and $P$. crenatus was reported to cause severe yield losses in very susceptible corn in Europe (Rivoal and Cook 1993). Additionally, $P$. thornei was responsible for wheat yield suppression in Oregon (Smiley et al. 2005).

The lance, pin, and stunt nematodes were found in nearly $50 \%$ of the fields sampled in Ohio, at mean population densities (averaged across positive fields) of 20,61 , and 23 nematodes $/ 100 \mathrm{~cm}^{3}$ soil, respectively. Compared with Ohio, incidence of the pin nematode was relatively low in Illinois and Iowa, 24.3 and $0.6 \%$, respectively (Tylka et al. 2011a; T. L. Niblack and H. D. Lopez-Nicora, personal communication), and lower incidence of stunt nematodes was reported in Iowa (4.8\%) compared with Ohio and Illinois (36\%). The suggested severe- and moderate-risk population thresholds, based on work done in Illinois (Niblack 2009), are 76-150 and 41-75 nematodes $/ 100 \mathrm{~cm}^{3}$ soil, respectively, for the lance nematode; and 501-1,000 and 101-500 nematodes $/ 100 \mathrm{~cm}^{3}$ soil, respectively, for the pin nematode.

Thirteen of the 28 Ohio counties surveyed had fields with lance nematode populations between the moderate- and severe-risk threshold levels, whereas 18 had at least one field with population density above the moderate damage threshold for the pin nematode,

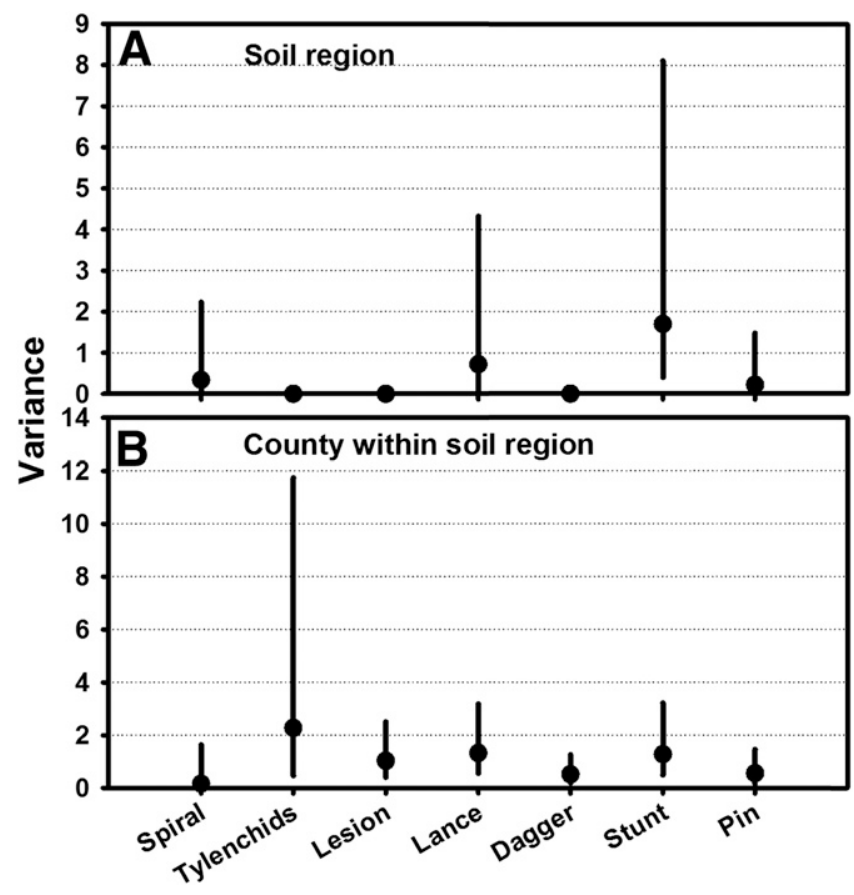

Fig. 5. Estimated variance parameters (dots) and $95 \%$ confidence intervals (erro bars) at the $\mathbf{A}$, soil region, and $\mathbf{B}$, county within soil region levels for the presence of spiral, tylenchids, lesion, lance, dagger, stunt, and pin nematodes in Ohio corn fields sampled between growth stages V3 and V6 during the 2013 and 2014 growing seasons. Between 15 and 16 fields were surveyed in 28 counties. Three species of lesion (Pratylenchus thornei, $P$. scribneri, and P. crenatus) and one each of spiral (Helicotylenchus pseudorobustus), lance (Hoplolaimus magnistylus), dagger (Xiphinema rivesi), stunt (Tylenchorhynchus claytoni), and pin (Paratylenchus neoamblycephalus) nematodes were identified.

Table 5. Estimated mean nematode incidence on the logit $(\hat{\beta})$ and original data $(\hat{p})$ scales, variances $\left(\hat{\sigma}_{R}^{2}\right.$ and $\left.\hat{\sigma}_{C}^{2}\right)$, and corresponding standard errors $(\mathrm{SE})$ and levels of significance $(P)$ from generalized linear mixed model analyses of the random effects of soil region and county within soil region on the presence of seven morphological groups of plant-parasitic nematodes in corn fields sampled between the V3 and V6 growth stages in 2013 and 2014

\begin{tabular}{|c|c|c|c|c|c|c|c|c|}
\hline \multirow[b]{2}{*}{ Nematode $^{\mathbf{a}}$} & \multirow[b]{2}{*}{$\hat{\beta}(S E)$} & \multirow[b]{2}{*}{$\hat{p}(S E)$} & \multicolumn{2}{|c|}{ Soil region } & \multicolumn{2}{|c|}{ County } & \multicolumn{2}{|c|}{$\left(\hat{\sigma}_{R}^{2}-\hat{\sigma}_{C}^{2}\right)^{\mathbf{b}}$} \\
\hline & & & $\hat{\sigma}_{R}^{2}(\mathrm{SE})$ & $P$ & $\hat{\sigma}_{C}^{2}(S E)$ & $P$ & $x^{2}$ & $P$ \\
\hline Spiral & $2.92(0.373)$ & $0.95(0.018)$ & $0.34(0.354)$ & 0.076 & $0.16(0.406)$ & 0.337 & 0.09 & 0.759 \\
\hline Tylenchids & $4.12(0.655)$ & $0.98(0.010)$ & $0\left(\ldots{ }^{c}\right)$ & $>0.999$ & $2.28(1.674)$ & $<0.001$ & $\ldots{ }^{c}$ & $\ldots{ }^{c}$ \\
\hline Lesion & $1.66(0.462)$ & $0.84(0.062)$ & $0\left(\ldots{ }^{c}\right)$ & $>0.999$ & $1.03(0.981)$ & $<0.001$ & $\ldots{ }^{c}$ & $\ldots{ }^{c}$ \\
\hline Lance & $-0.17(0.429)$ & $0.46(0.107)$ & $0.72(0.678)$ & 0.042 & $1.32(0.579)$ & $<0.001$ & 0.36 & 0.546 \\
\hline Dagger & $-0.58(0.175)$ & $0.36(0.040)$ & $0\left(\ldots{ }^{\mathrm{c}}\right)$ & $>0.999$ & $0.52(0.244)$ & $<0.001$ & $\ldots{ }^{c}$ & $\ldots{ }^{c}$ \\
\hline Stunt & $-0.20(0.590)$ & $0.45(0.146)$ & $1.70(1.215)$ & 0.001 & $1.28(0.593)$ & $<0.001$ & 0.12 & 0.732 \\
\hline Pin & $0.31(0.263)$ & $0.58(0.064)$ & $0.22(0.244)$ & 0.097 & $0.56(0.287)$ & $<0.001$ & 0.62 & 0.430 \\
\hline
\end{tabular}

a Three species of lesion (Pratylenchus thornei, P. scribneri, and P. crenatus) and one each of spiral (Helicotylenchus pseudorobustus), lance (Hoplolaimus mag nistylus), dagger (Xiphinema rivesi), stunt (Tylenchorhynchus claytoni), and pin (Paratylenchus neoamblycephalus) nematodes. The group tylenchids represents several genera morphologically similar to members of the subfamily Tylenchinae (NCBI Taxonomy) including Cephelenchus, Filenchus, Malenchus, and Tylenchus.

${ }^{\mathrm{b}} \chi^{2}$ statistic and corresponding level of significance $(P)$ from likelihood-ratio test of the difference in estimated variance between soil region and county within soil region.

${ }^{\mathrm{c}}$ Since the estimated variance for soil region is 0 , the corresponding SE and test statistic for the difference in estimated variances between soil region and county within soil region are undefined. 
including five above the suggested severe risk level. Three Ohio counties had at least one field with stunt populations above the 100 nematodes $/ 100 \mathrm{~cm}^{3}$ soil severe damage threshold level proposed by Tylka et al. (2011a). Tylenchorhynchus claytoni, the species of stunt nematode identified in this study, was previously reported to be an important pathogen of corn in the U.S. Midwest (Nelson 1955). Results from greenhouse studies demonstrated that 200 nematodes of this species per pot caused some damage, 500 caused severe stunting, and 50 had no effect on corn (Nelson 1956).

Although dagger nematodes were found in $37 \%$ of the samples, all sampled fields had populations below the severe-risk damage threshold (30-40 nematodes $/ 100 \mathrm{~cm}^{3}$ soil) suggested by Tylka et al. (2011a), and only five of the 425 fields had populations (between 20 and 26 nematodes $/ 100 \mathrm{~cm}^{3}$ soil) approaching this threshold. Ring, stubby-root, and cyst were infrequently or never found above their respective damage thresholds, whereas needle, root-knot, and sheath nematodes were not found in any of the samples collected in this study. In the case of the cyst nematode, confirmed morphologically as being Heterodera glycines, the soybean cyst nematode (SCN, data not shown), low numbers were due to the fact that it is a pathogen of soybean and not corn, and rotating soybean with corn causes its population to decrease (Chen et al. 2001; Niblack 2005). In addition, since our focus was on nematodes known to affect corn, our sampling and extraction protocols were not appropriate for detecting and enumerating SCN, further contributing to its relatively low incidence and population density. However, for the other nematodes not found (or at low incidence and density) in this study, one cannot conclude that they are not present or unimportant in the state, since only 28 counties were surveyed, and only $15-16$ fields were sampled in each county. Several of these genera were found to be associated with corn in other related studies (Norton and Nyvall 2011; Tylka et al. 2011a).

The reasons for the absence or low incidence/density of the aforementioned nematodes in Ohio may range from differences in soil type, farming practices, sampling date, and sampling and extraction techniques. For example, needle nematodes are often highly localized and restricted largely to very sandy soils (at least $49 \%$ sand) (Norton and Hoffmann 1975). Only 7\% of the soil samples collected in this study had at least 49\% sand. Furthermore, Tylka et al. (2011b) suggested that when sampling for PPNs and the needle nematode is suspected to be present, samples should be collected in the spring or fall. All samples in the current study were collected in June and early July. Moreover, because some PPNs may be easily ruptured during transport and handling of soil samples (Tylka et al. 2011b), it is possible that some individuals were simply not recovered. It is also possible that some of the nematodes were simply not present in the corn fields sampled, but given their economic importance, further research will be needed to ascertain whether they are present in counties/fields not sampled in this study.

In addition to determining which PPNs are present in corn fields in Ohio, in which counties, and at what population densities, we successfully characterized the heterogeneity of these organisms at multiple spatial scales. Several studies have investigated the heterogeneity of fungal diseases of aboveground plant parts (Hughes and Samita 1998; Hughes et al. 1998; Kriss et al. 2012; Nita et al. 2008; Wilhelm and Jones 2005), and a few have reported on the
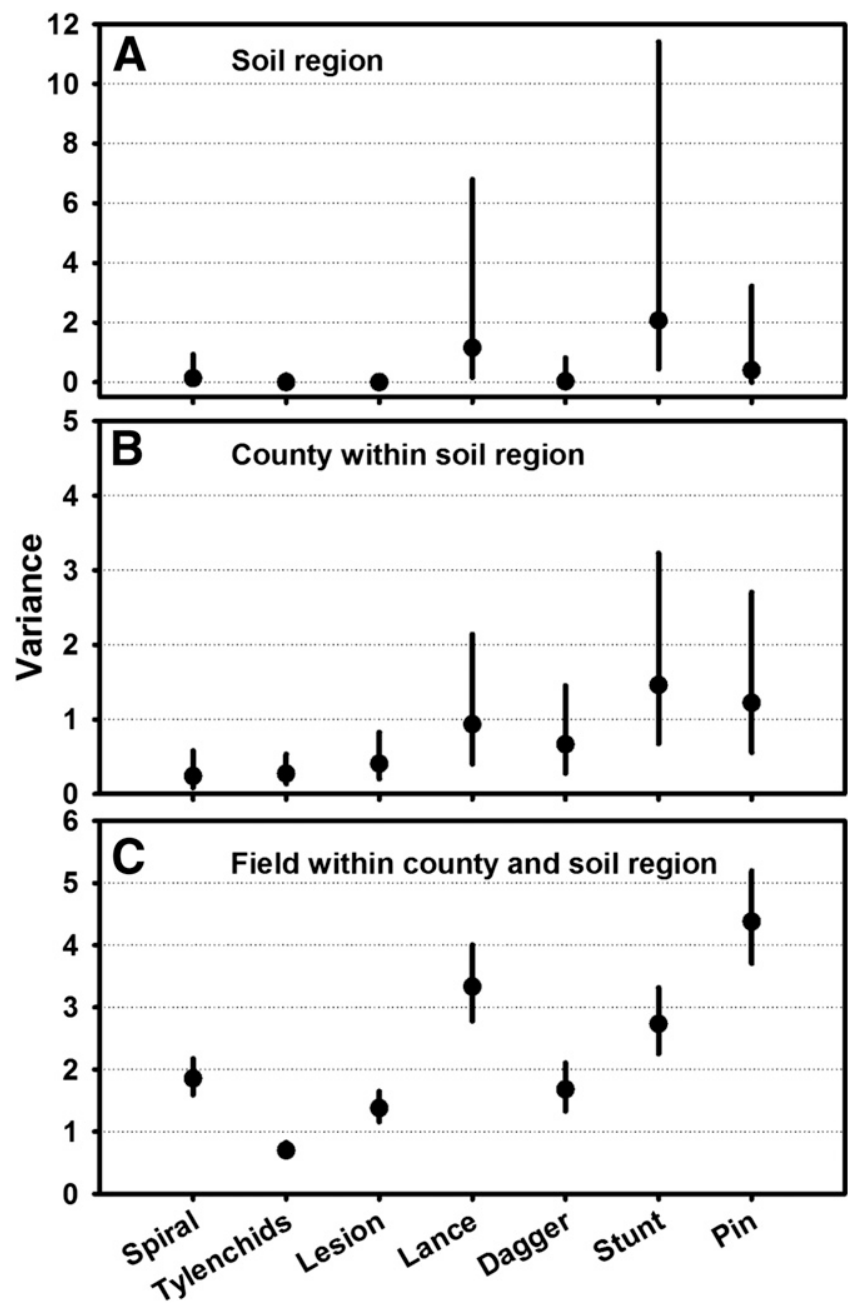

Fig. 6. Estimated variance parameters (dots) and $95 \%$ confidence intervals (error bars) at the A, soil region, B, county within soil region, and C, field within county and soil region levels for population density (nematodes per $100 \mathrm{~cm}^{3}$ soil) of spiral, tylenchids, lesion, lance, dagger, stunt, and pin nematodes in Ohio corn fields sampled between growth stages V3 and V6 during the 2013 and 2014 growing seasons. Between 15 and 16 fields were surveyed in 28 counties. Three species of lesion (Pratylenchus thornei, P. scribneri, and P. crenatus) and one each of spiral (Helicotylenchus pseudorobustus), lance (Hoplolaimus magnistylus), dagger (Xiphinema rivesi), stunt (Tylenchorhynchus claytoni), and pin (Paratylenchus neoamblycephalus) nematodes were identified.

Table 6. Estimated variances $\left(\hat{\sigma}_{R}^{2}, \hat{\sigma}_{C}^{2}\right.$, and $\left.\hat{\sigma}_{F}^{2}\right)$ and corresponding standard errors (SE) and level of significance $(P)$ from generalized linear mixed model analyses of the random effects of soil region, county within soil region, and field within county and soil region on population density of seven morphological groups of plant-parasitic nematodes in corn fields sampled between the V3 and V6 growth stages in 2013 and 2014

\begin{tabular}{|c|c|c|c|c|c|c|}
\hline \multirow[b]{2}{*}{ Nematode $^{a}$} & \multicolumn{2}{|c|}{ Soil region } & \multicolumn{2}{|c|}{ County } & \multicolumn{2}{|c|}{ Field } \\
\hline & $\hat{\sigma}_{R}^{2}(S E)$ & $P$ & $\hat{\sigma}_{C}^{2}(S E)$ & $P$ & $\hat{\sigma}_{F}^{2}(S E)$ & $P$ \\
\hline Spiral & $0.14(0.137)$ & 0.054 & $0.24(0.111)$ & $<0.001$ & $1.85(0.148)$ & $<0.001$ \\
\hline Tylenchids & $<0.01(0.047)$ & 0.499 & $0.27(0.098)$ & $<0.001$ & $0.70(0.059)$ & $<0.001$ \\
\hline Lesion & $0(\ldots \mathrm{b})$ & $>0.999$ & $0.41(0.143)$ & $<0.001$ & $1.38(0.123)$ & $<0.001$ \\
\hline Lance & $1.16(0.952)$ & 0.005 & $0.93(0.389)$ & $<0.001$ & $3.33(0.310)$ & $<0.001$ \\
\hline Dagger & $0.03(0.142)$ & 0.415 & $0.67(0.279)$ & $<0.001$ & $1.68(0.195)$ & $<0.001$ \\
\hline Stunt & $2.07(1.575)$ & 0.001 & $1.46(0.572)$ & $<0.001$ & $2.73(0.268)$ & $<0.001$ \\
\hline Pin & $0.40(0.486)$ & 0.119 & $1.22(0.482)$ & $<0.001$ & $4.38(0.376)$ & $<0.001$ \\
\hline
\end{tabular}

${ }^{a}$ Three species of lesion (Pratylenchus thornei, P. scribneri, and P. crenatus) and one each of spiral (Helicotylenchus pseudorobustus), lance (Hoplolaimus magnistylus), dagger (Xiphinema rivesi), stunt (Tylenchorhynchus claytoni), and pin (Paratylenchus neoamblycephalus) nematodes. The group tylenchids represents several genera morphologically similar to members of the subfamily Tylenchinae (NCBI Taxonomy) including Cephelenchus, Filenchus, Malenchus, and Tylenchus.

${ }^{\mathrm{b}}$ Since the estimated variance for soil region is 0 , the corresponding SE is undefined. 
spatial pattern of PPNs in research plots (Gavassoni et al. 2001, 2007), but to our knowledge, this was the first to utilize likelihoodbased methods to quantify nematode variability at multiple spatial scales through generalized linear mixed model analyses. Population density was more variable at the lowest (among fields) level in the spatial hierarchy than at the highest level (among soil regions). These findings contrast with those reported by Kriss et al. (2012) for the spatial heterogeneity of Fusarium head blight (caused by Fusarium graminearum) incidence in commercial wheat fields, but are consistent with results from a survey of PPNs in wheat fields in Kansas and eastern Colorado (Todd et al. 2014) and with those from a study by Nita et al. (2008) on the heterogeneity of the incidence of Phomopsis cane and leaf spot (caused by Phomopsis viticola) in commercial vineyards.

The spatial heterogeneity of any given plant disease or pathogen could be attributed to several pathogen-, host-, and environmentrelated factors, as well as production and cropping practices (Kriss et al. 2012; Wilhelm and Jones 2005). Moreover, inherent properties of a disease/pathogen that are related to its general biology/ epidemiology may affect differences in variability within a spatial hierarchy. As it relates to the nematodes in this study, field-specific factors and our relatively small sample size, coupled with the fact that PPNs are known to have an aggregated spatial distribution pattern (Holguin et al. 2015), may have contributed to the relatively high field-to-field variability observed here. To that end, Simon et al. (2018) showed through logistic regression analyses that tillage, cropping sequence, and soil $\mathrm{pH}$, silt content, and electrical conductivity all affected the odds of several of the nematodes detected in this study being present or exceeding certain population thresholds. By virtue of the sampling protocol used here, these factors were likely less variable among soil regions and counties within soil regions, than among fields within counties and soil regions, resulting in lower variability at the two higher levels in the hierarchy. For instance, fields under each of the evaluated tillage and crop rotational schemes were fairly well distributed across soil regions, likely reducing the effects of these factors on the variability of PPN populations at this spatial scale.

From this study, we conclude that most of the corn fields sampled had PPNs below the suggested damage thresholds. Incidence and population density varied among nematodes, and for a given morphological group, among soil regions, counties within soil regions, and fields within counties and soil region. However, there were individual fields in several counties with mean population densities above the proposed damage thresholds for the lesion, lance, spiral, and stunt nematodes. This coupled with the fact that three species of PPNs were reported for the first time in the state of Ohio and the prevalence of three species of the lesion nematode underscore the need for follow-up research to: i) further characterize PPN populations in the state, ii) quantify relationships between populations of the most frequently occurring PPNs and yield in order to establish Ohio-specific damage thresholds, and iii) identify location-specific risk factors contributing to the high incidence and population density observed in some fields and counties.

\section{Acknowledgments}

Special thanks to the following OSU students, staff, and county extension educations and corn producers for assistance with sample collection: J. D. Salgado, K. B. Mills, W. B. Moreas, F. D. Lana, J. Engle, K. Davis, A. L. Rugh, A. Kerby, A. Pund, T. I. Ralston, K. Miller, A. Small, N. Raab, E. Richer, A. Sundermeier, G. Ruff, S. Noggle, M. Gastier, J. V. Overocker, C. Jagger, W. Dellinger, A. Mead, D. Brown, D. Riethman, D. Kreager, P. Bennett, J. Iles, M. Estadt, K. Ford, T. Corboy, T. Nye, S. Brady, D. Dugan, G. Neal, J. Fisher, B. Bergefurd, E. Dailey, T. West, J. Shriner, Mr. Davidson, Mr. Watts, Mr. Foster, Mr. Price, Mr. Hogbarn, Mr. Martin, Mr. Smith, Mr. Kirk, Mr. Martin, Mr. Phillip, Mr. Woelke, Mr. Shaffer, Mr. Reynolds, Mr. Shaffer, Mr. Belleville, Mr. Stickle, Mr. Akers, Mr. Kranz, Mr. Lehman, Mr. Biser, Mr. Scherer, Mr. Carrol, Mr. Corcoran, Mr. Benner, Mr. Ewing, Mr. Hudson, Mr. Farner, Mr. Fulton, Mr. Witt, Mr. Linkhart, Mr. Swaim, Mr. Jacob, Mr. Rhonemus, Mr. Ball, Mr. Louiso, Mr. Cluxton, Mr. Carr, Mr. Carraher, Mr. Roehm, Mr. Gunter, Mr. Jodrey, Mr. Gauche, Mr. Stingley, Mr. Kelly, Mr. Clark, Mr. Lung, Mr. Stahl, Mr. Dressback, Mr. Aukeman, Mr. Noecker, Mr. Blue, Mr. Clifton, Mr. Conn, Mr. Stuckey, Mr. Fannin, Mr. Rockhold, Mr. Gustin, Mr. Lee, Mr. Lee-Mar, Mr. Lowe, Mr. Delong, Mr. Wedding, Mr. Mc Dowell, Mr. Lokai, Mr. Haerr, Mr. Shawhan, Mr. Mc Dorman, Mr. Cessna, Mr. Sailor, Mr. Seger, Mr. Davis, Mr. Finkebine,
Mr. Slonkosky, Mr. Lehman, Mr. Wigwam, Mr. Greene, Mr. Wenger, Mr. Henry, Mr. Dete, Mr. Hellwarth, Mr. Wenning, Mr. Suhr, Mr. Drake, Mr. Davidson, Mr. Waugh, Mr. Brown, Mr. Wenninger, Mr. Wood, Mr. Thompson, Mr. Eddy, Mr. Zylstra, Mr. Napolean, Mr. Bokelman, Mr. Jacobs, Mr. Engler, Mr. Vorwerk, Mr. Plotts, Mr. Cordes, Mr. Wendth, Mr. Stockman, Mr. Richer, Mr. Emmons, Mr. Aeschliman, Mr. Myers, Mr. Sheets, Mr. LeMaster, Mr. Jones, Mr. Williams, Mrs. Lewis, Mr. Alt, Mr. Wolfe, Mr. Wilson, Mr. Wuertz, Mr. Staley, Mr. Mc Chesney, Mr. Harris, Mr. Meimer, Mr. Webber, and Mr. Radcliffe.

\section{Literature Cited}

Abendroth, L. J., Elmore, R. W., Boyer, M. J., and Marlay, S. K. 2011. Corn Growth and Development. PMR 1009, Iowa State University Extension, Ames, IA.

Alby, T., Ferris, J. M., and Ferris, V. R. 1983. Dispersion and distribution of Pratylenchus scribneri and Hoplolaimus galeatus in soybean fields. J. Nematol. 15:418-426.

Barker, D., Culman, S., Dorrance, A., Fulton, J., Haden, R., Lentz, E., Lindsey, A., Lindsey, L., Loux, M., McCoy, E., Michel, A., Noel, J., Paul, P., Sulc, M., Thomison, P., Tilmon, K., and Witter, J. 2017. Ohio Agronomy Guide, 15th Ed. The Ohio State University Bull. 472.

Batista da Silva, M. 2013. Studies on Extraction and Control of Plant-Parasitic Nematodes on Corn. M.S. thesis. Department of Plant Pathology and Microbiology, Iowa State University, Ames, IA.

Castillo, P., and Vovlas, N. 2007. Pratylenchus (Nematoda: Pratylenchidae) Diagnosis, biology, pathogenicity and management. D. J. Hunt and R. N. Perry, eds. Nematology Monographs and Perspectives 6. Brill, Leiden, The Netherlands.

Caveness, F. E. 1974. Plant-parasitic nematode population differences under notillage and tillage soil regimes in western Nigeria. J. Nematol. 6:138.

Chen, S., Porter, P. M., Reese, C. D., and Stienstra, W. C. 2001. Crop sequence effects on soybean cyst nematode and soybean and corn yields. Crop Sci. 41: 1843-1849.

De Ley, P., Felix, M.-A., Frisse, L. M., Nadler, S. A., Sternberg, P. W., and Thomas, W. K. 1999. Molecular and morphological characterization of two reproductively isolated species with mirror image anatomy (Nematoda: Cephalobidae). Nematology 1:591-612.

Egunjobi, O. A. 1974. Nematodes and maize growth in Nigeria. II. Effects of some amendments on populations of Pratylenchus brachyurus and on the growth and production of maize (Zea mays) in Nigeria. Nematol. Mediterr. 3:5-73.

Florini, D. A., Lorai, R., and Kotcon, J. B. 1987. Influence of edaphic factors and previous crop on Pratylenchus spp. population densities in potatoes. J. Nematol. 19:85-92.

Fortuner, R., Maggenti, A. R., and Whittaker, L. M. 1984. Morphometrical variability in Helicotylenchus Steiner, 1945. 4: Study of field populations of H. pseudorobustus and related species. Rev. Nematol. 7:121-135.

Gavassoni, W. L., Tylka, G. L., and Munkvold, G. P. 2001. Relationships between tillage and spatial patterns of Heterodera glycines. Phytopathology 91:534-545.

Gavassoni, W. L., Tylka, G. L., and Munkvold, G. P. 2007. Effects of tillage practices on dissemination and spatial patterns of Heterodera glycines and soybean yield. Plant Dis. 91:973-978.

Gbur, E. E., McCarter, K. S., Durham, S., Young, L. J., Christman, M., West, M. and Kramer, M. 2012. Analysis of generalized linear mixed models in the agricultural and natural resource sciences. American Society of Agronomy, Soil Science Society of America, Crop Science Society of America, Madison, WI.

Handoo, Z. A. 2000. A key and diagnostic compendium to the species of the genus Tylenchorhynchus Cobb, 1913 (Nematoda: Belonolaimidae). J. Nematol. 32: 20-34.

Handoo, Z. A., and Golden, A. M. 1989. A key and diagnostic compendium to the species of the genus Pratylenchus Filipjev, 1936 (lesion nematodes). J. Nematol. 21:202-218.

Handoo, Z. A., and Golden, A. M. 1992. A key and diagnostic compendium to the species of the genus Hoplolaimus Daday, 1905 (Nematoda: Hoplolaimidae). J. Nematol. 24:45-53.

Holguin, C. M., Gerard, P., Mueller, J. D., Khalilian, A., and Agudelo, P. 2015. Spatial distribution of reniform nematode in cotton as influenced by soil texture and crop rotations. Phytopathology 105:674-683

Hübschen, J., Kling, L., Ipach, U., Zinkernagel, V., Brown, D., and Neilson, R. 2004. Development and validation of species-specific primers that provide a molecular diagnostic for virus-vector longidorid nematodes and related species in German viticulture. Eur. J. Plant Pathol. 110:883-891.

Hughes, G., Munkvold, G. P., and Samita, S. 1998. Application of the logisticnormal-binomial distribution to the analysis of Eutypa dieback disease incidence. Int. J. Pest Manag. 44:35-42.

Hughes, G., and Samita, S. 1998. Analysis of patterns of pineapple mealybug wilt disease in Sri Lanka. Plant Dis. 82:885-890.

Jenkins, W. R. 1964. A rapid centrifugal-flotation technique for separating nematodes from soil. Plant Dis. Rep. 48:692.

Kriss, A. B., Paul, P. A., and Madden, L. V. 2012. Characterizing heterogeneity of disease incidence in a spatial hierarchy: A case study from a decade of observations of Fusarium head blight of wheat. Phytopathology 102:867-877.

Lamberti, F., and Carone, M. 1991. A dichotomous key for the identification of species of Xiphinema (Nematoda:Dorylaimida) within the X. americanum group. Nematol. Mediterr. 19:341-348. 
Lawn, D. A., and Noel, G. R. 1986. Field interrelationships among Heterodera glycines, Pratylenchus scribneri and three other nematode species associated with soybean. J. Nematol. 18:98.

Littell, R. C., Milliken, G. A., Stroup, W. W., Wolfinger, R. D., and Schabenberger, O. 2006. SAS System for Mixed Models. SAS Institute, Cary, NC.

Mai, W. F., and Mullin, P. G. 1996. Plant-Parasitic Nematodes: A Pictorial Key to Genera, 5th Ed. Cornell University Press, Ithaca, NY.

Nelson, R. R. 1955. Nematode parasites of com in the coastal plain of North Carolina. Plant Dis. Rep. 39:818-819.

Nelson, R. R. 1956. Resistance to the stunt nematode in com. Plant Dis. Rep. 40: 635-639.

Niblack, T. L. 1992. Pratylenchus, Paratylenchus, Helicotylenchus, and other nematodes on soybean in Missouri. J. Nematol. 24(4S):738.

Niblack, T. L. 2005. Soybean cyst nematode management reconsidered. Plant Dis. 89:1020-1026.

Niblack, T. L. 2009. Nematodes. Pages 9-18 in: Illinois Agronomy Handbook, 24th Ed. E. Nafziger, ed. University of Illinois Extension, Urbana, IL.

Nita, M., Ellis, M. A., and Madden, L. V. 2008. Variation in disease incidence of Phomopsis cane and leaf spot of grape in commercial vineyards in Ohio. Plant Dis. 92:1053-1061.

Norton, D. C. 1983. Maize nematode problems. Plant Dis. 67:253-256.

Norton, D. C. 1984. Nematode parasites of corn. Pages 61-94 in: Plant and Insect Nematodes. W. R. Nickle, ed. Marcel Dekker, New York.

Norton, D. C., and Hoffmann, J. K. 1974. Distribution of Selected Plant Parasitic Nematodes Relative to Vegetation and Edaphic Factors. J. Nematol. 6:81-86.

Norton, D. C., and Hoffmann, J. K. 1975. Longidorus breviannulatus n. sp. (Nematoda: Longidoridae) associated with stunted corn in Iowa. J. Nematol. 7:168-171.

Norton, D. C., and Nyvall, R. F. 2011. Nematodes that attack corn in Iowa. Online. Coop. Ext. Publ. PM 1027. Iowa State University, Ames, IA.

Norton, D. C., Tollefson, J., Hinz, P., and Thomas, S. H. 1978. Corn yield increases relative to non-fumigant chemical control of nematodes. J. Nematol. 10:160-166.

Parmelee, R. W., and Alston, D. G. 1986. Nematode trophic structure in conventional and no-tillage agroecosystems. J. Nematol. 18:403-407.

Raski, D. J. 1975. Revision of the genus Paratylenchus Micoletzky, 1922, and descriptions of new species. Part II, of three parts. J. Nematol. 7:274-295.

Rivoal, R., and Cook, R. 1993. Nematode pests of cereals. Pages 259-303 in: Plant Parasitic Nematodes in Temperate Agriculture. K. Evans, et al., eds. CAB Int., Wallingford, England.

Simon, A. C. M. 2015. Investigating the Presence and Population Densities of Plant-Parasitic Nematodes and the Influence of Soil Region, Cropping
Practices and Soil Properties on these Nematodes in Corn Fields in Ohio. M.S. thesis. Department of Plant Pathology, The Ohio State University, Columbus.

Simon, A. C. M, Lopez-Nicora, H. D., Niblack, T. L., Dayton, E. A., Tomashefski, D., Jones, F. S., and Paul, P. A. 2018. Cropping practices and soil properties associated with plant-parasitic nematodes in corn fields in Ohio. Plant Dis. 102: 2519-2530.

Smiley, R. W., Whittaker, R. G., Gourlie, J. A., and Easley, S. A. 2005 Pratylenchus thornei associated with reduced wheat yield in Oregon. J. Nematol. 37:45-54.

Stroup, W. W. 2013. Generalized Linear Mixed Models: Modern Concepts, Methods and Applications. Chapman \& Hall/CRC Texts in Statistical Science. CRC Press, Boca Raton, FL.

Thomas, S. H. 1978. Population densities of nematodes under seven tillage regimes. J. Nematol. 10:24-27.

Todd, T. C. 1991. Effects of cropping regime on populations of Belonolaimus sp. and Pratylenchus scribneri in sandy soil. J. Nematol. 23:646-651.

Todd, T. C., Appel, J. A., Vogel, J., and Tisserat, N. A. 2014. Survey of plantparasitic nematodes in Kansas and Eastern Colorado wheat fields. Plan Health Prog. doi:10.1094/PHP-RS-14-0003

Tylka, G. L., Sisson, A. J., Jesse, L. C., Kennicker, J., and Marett, C. C. 2011a Testing for plant-parasitic nematodes that feed on corn in Iowa 2000-2010. Plant Health Prog. doi:10.1094/PHP-2011-1205-01-RS

Tylka, G. L., Todd, T. C., Niblack, T. L., MacGuidwin, A. E., and Jackson, T. 2011b. Sampling for plant-parasitic nematodes in corn strip trials comparing nematode management products. Plant Health Prog. doi:10.1094/PHP-20110901-01-DG

Vrain, T. C., Wakarchuk, D. A., Lévesque, A. C., and Hamilton, R. I. 1992. Intraspecific rDNA restriction fragment length polymorphism in the Xiphinema americanum group. Fundam. Appl. Nematol. 15:563-573.

Wallace, M. K., Rust, R. H., Hawkins, D. M., and MacDonald, D. H. 1993. Correlation of edaphic factors with plant-parasitic nematode population densities in a forage field. J. Nematol. 25:642-653.

Wilhelm, K. P., and Jones, R. K. 2005. Meso- and microscale patterns of Fusarium head blight in spring wheat fields in Minnesota. Plant Dis. 89: 474-479.

Yeates, G. W., Bongers, T., de Goede, R. G. M., Freckman, D. W., and Georgieva S. S. 1993. Feeding habits in soil nematode families and genera - an outline for soil ecologists. J. Nematol. 25:315-331.

Zirakparvar, M. E. 1980. Host range of Pratylenchus hexincisus and its pathogenicity on corn, soybean, and tomato. Phytopathology 70:749-753. 